\title{
Autoantibody to RNA Polymerase I in Scleroderma Sera
}

\author{
Georg Reimer," Kathleen M. Rose, ${ }^{\ddagger}$ Ulrich Scheer," and Eng M. Tan* \\ ${ }^{*} W$. M. Keck Autoimmune Disease Center, Department of Basic and Clinical Research, Scripps Clinic and Research Foundation, \\ La Jolla, California 92037; ${ }^{\ddagger}$ University of Texas Medical School, Department of Pharmacology, Houston, Texas 77225; \\ ${ }^{\S}$ German Cancer Research Center, Institute of Cell and Tumor Biology, D-6900 Heidelberg, Federal Republic of Germany
}

\begin{abstract}
Autoantibodies to components of the nucleolus are a unique serological feature of patients with scleroderma. There are autoantibodies of several specificities; one type produces a speckled pattern of nucleolar staining in immunofluorescence. In actinomycin $D$ and 5,6-dichloro- $\beta$-D-ribofuranosylbenzimidazoletreated Vero cells, staining was restricted to the fibrillar and not the granular regions. By double immunofluorescence, specific rabbit anti-RNA polymerase $I$ antibodies stained the same fibrillar structures in drug-segregated nucleoli as scleroderma sera. Scleroderma sera immunoprecipitated 13 polypeptides from $\left[{ }^{35}\right.$ S]methionine-labeled $\mathrm{HeLa}$ cell extract with molecular weights ranging from 210,000 to 14,000 . Similar polypeptides were precipitated by rabbit anti-RNA polymerase I antibodies, and their common identities were confirmed in immunoabsorption experiments. Microinjection of purified IgG from a patient with speckled nucleolar staining effectively inhibited ribosomal RNA transcription. Autoantibodies to RNA polymerase I were restricted to certain patients with scleroderma and were not found in other autoimmune diseases.
\end{abstract}

\section{Introduction}

Patients with systemic autoimmune diseases spontaneously produce antibodies against a variety of cellular components (1). DNA and histones are among nuclear autoantigens with known structure and function. Other nuclear antigens are either nuclear proteins or RNA-protein complexes that have been partially characterized and called Ul-RNP, Sm, SS-B/La, Jo-1, Scl-70, and centromere/kinetochore antigens (2-10). There are expectations that knowledge of the structure and function of these autoantigens could lead to a better understanding of the etiopathogenesis of autoimmune diseases and provide better reagents to construct accurate diagnostic probes. Furthermore, some of these naturally occurring autoantibodies have been used successfully as probes in molecular and cellular biology. For example, antibodies against Ul-RNP were shown to inhibit splicing of heterogenous nuclear RNA, thus implicating an important role of this ribonucleoprotein in the processing of precursor

Address reprint requests to Eng M. Tan, M.D., W. M. Keck Autoimmune Disease Center, Scripps Clinic and Research Foundation, 10666 North Torrey Pines Road, La Jolla, CA 92037. Dr. Reimer's current address is Dermatologische Universitatsklinik, Hartmannstr. 14, D-8520 Erlangen, FRG. 1986.

Received for publication 28 May 1986 and in revised form 27 August

J. Clin. Invest.

(c) The American Society for Clinical Investigation, Inc.

0021-9738/87/01/0065/08 \$1.00

Volume 79, January $1987,65-72$
mRNA (11). Autoantibodies against SS-B/La identified this nuclear ribonucleoprotein as possibly involved in the transport of RNA, particularly products of RNA polymerase III, including virus encoded RNAs EBER 1 and 2 of Epstein-Barr virus (12). More recent evidence suggests that the SS-B/La particle is either a termination factor for RNA polymerase III or is involved in posttermination processing events (13). Recently, anticentromere/kinetochore antibodies from scleroderma patients have facilitated identification and molecular cloning of a common human kinetochore protein (14).

Antinucleolar antibodies are part of the spectrum of autoantibodies present in scleroderma (15-17). This systemic autoimmune disease is characterized by microvascular lesions and abnormalities of the immune system leading to fibrosis of the skin and certain target organs. One of the antigens reactive with scleroderma antibodies was recently shown to be a novel nucleolar 7-2 ribonucleoprotein (18-19). U-3 ribonucleoprotein was also shown to be part of a complex precipitated by certain antinucleolar autoantibodies from scleroderma patients (18). These autoantibodies were found to interact with a basic nucleolar protein of mol wt 34,000 (20), termed fibrillarin, as this protein was shown to be associated with the fibrillar component of nucleoli (21). The identity of other nucleolar autoantigens in scleroderma, however, is unknown.

In this study, we present data that show that the antigens recognized by a subgroup of antinucleolar autoantibodies consist of RNA polymerase I complex. The clinical association of this antibody specificity was with the diffuse form of scleroderma.

\section{Methods}

Sera. Included in this study are sera from 208 scleroderma patients, kindly provided by $O$. P. Hornstein (Erlangen, FRG), H. Mensing (Hamburg, FRG), M. Meurer (Munich, FRG), D. S. Prince (Birmingham, AL), R. A. Kaplan (San Diego, CA), J. G. Curd and G. W. Williams (La Jolla, CA). Sera from more than 100 patients with other systemic autoimmune diseases, including systemic lupus erythematosus (SLE), ${ }^{1}$ mixed connective tissue disease (MCTD), drug-induced lupus, dermatomyositis, polymyositis, and rheumatoid arthritis, and 20 normal individuals served as controls. All scleroderma patients fulfilled the preliminary criteria for the diagnosis of progressive systemic sclerosis (22). A rabbit antiserum to RNA polymerase I was used as a reference. This antiserum was produced in the laboratory of Dr. K. M. Rose by immunization of a rabbit with purified RNA polymerase I from Morris hepatoma $3924 \mathrm{~A}$ in a manner described previously (23). Rabbit antiRNA polymerase I antibodies, as used in the present study, had previously been used in a series of other studies to localize RNA polymerase I in normal cells (24) and cells treated with the nucleolus segregating drug 5,6 -dichloro- $\beta$-D-ribofuranosylbenzimidazole (DRB) (25). These antibodies had been used further to show induction of increased amount

1. Abbreviations used in this paper: DRB, 5,6-dichloro- $\beta$-D-ribofuranosylbenzimidazole; MCTD, mixed connective tissue disease; PMSF, phenylmethylsulfonylfluoride; SLE, systemic erythematosus. 
and activity of RNA polymerase I in mouse B lymphocytes treated with lipopolysaccharide (26).

Indirect immunofluorescence. Indirect immunofluorescence was performed with Hep-2 cells (Bion Enterprises, Ltd., Park Ridge, IL) as substrate. Other substrates included HeLa and Vero cells, grown on microscopic slides and fixed in ice cold acetone/methanol 3:1 for $3 \mathrm{~min}$, and rat liver cryostat sections. Further tissues included chicken liver and different organ sections from Xenopus laevis. Sera were diluted starting at 1:40 in phosphate-buffered saline (PBS), $\mathrm{pH}$ 7.4. A fluorescein (Behring Diagnostic, La Jolla, CA) and a rhodamine-labeled goat anti-human IgG conjugate (Tago, Inc., Burlingame, CA) were used. A fluoresceinlabeled goat anti-rabbit IgG conjugate was obtained from Tago, Inc. Intensity of immunofluorescence staining was graded weak $(+)$, moderate $(++)$, or strong $(+++)$. Results were read on an Ortholux II fluorescence microscope with a Ploempak vertical illuminator (E. Leitz, Inc., Rockleigh, NJ) using a NPL Fluortar 100/1.32 oil immersion objective. Double immunofluorescence staining was performed as described (27).

Drug studies. Segregation of nucleoli in tissue culture Vero cells into fibrillar and granular regions was induced by the addition of $0.2 \mu \mathrm{g} / \mathrm{ml}$ actinomycin D to the culture medium for $4 \mathrm{~h}$ or of $50 \mu \mathrm{g} / \mathrm{ml} \mathrm{DRB}$, a halogenated adenosine analogue, for $6 \mathrm{~h}$. Both drugs were purchased from Behring Diagnostics. After drug treatment, cells were fixed in acetone/methanol 3:1 and processed for immunofluorescence as described above.

Electron microscopic immunocytochemistry. Frozen sections (5- $\mu \mathrm{m}$ thickness) of normal and regenerating rat liver were fixed in acetone at $-20^{\circ} \mathrm{C}$ for $10 \mathrm{~min}$, air dried, and incubated with scleroderma serum S18 or rabbit anti-RNA polymerase I antibodies diluted 1:100 in PBS for 2 h. After several washes in PBS, goat anti-human IgG or goat anti-rabbit IgG coupled to colloidal gold (5-nm diameter; Janssen Life Sciences Products, Beerse, Belgium) was added at a dilution of 1:4. After overnight incubation at $4^{\circ} \mathrm{C}$, the specimens were fixed and processed for electron microscopy as described in detail elsewhere (24).

Radiolabeling of cells. HeLa cells were cultured in monolayers and radiolabeled for $20 \mathrm{~h}$ with $\left[{ }^{35} \mathrm{~S}\right]$ methionine or $\left[{ }^{32} \mathrm{P}\right]$ orthophosphate (New England Nuclear, Boston, MA) at $0.1 \mathrm{mCi} / \mathrm{ml}$ in methionine- or phosphate-free medium, respectively, as described (28). The cells were then washed once in PBS and harvested with a rubber policeman in ice cold buffer A containing $10 \mathrm{mM}$ Tris- $\mathrm{HCl}$ ( $\mathrm{pH} 7.4), 150 \mathrm{mM} \mathrm{NaCl}, 1.5 \mathrm{mM}$ $\mathrm{MgCl}_{2}, 0.5 \%$ Nonidet $\mathrm{P}-40$, supplemented with $23 \mathrm{U} / \mathrm{ml}$ kallikrein inactivator (Behring Diagnostics) and $2 \mathrm{mM}$ phenylmethylsulfonylfluoride (PMSF) to minimize proteolytic degradation. The cells were then freezethawed twice and centrifuged at $10,000 \mathrm{~g}$ for $15 \mathrm{~min}$, and the supernatant was stored at $-70^{\circ} \mathrm{C}$ until used. $\sim 10 \mathrm{mg}$ protein were extracted from HeLa cells grown in $150 \times 25-\mathrm{mm}$ tissue culture dish.

Immunoprecipitation. All experiments were performed at $0-4^{\circ} \mathrm{C}$ as described (28) with modifications. In brief, serum aliquots of $10 \mu \mathrm{l}$ were incubated with $100 \mu$ l of protein A Sepharose CL-4B (Pharmacia, Inc., Uppsala, Sweden) at $10 \%$ (vol/vol) suspension in buffer B supplemented with $2 \mathrm{mg} / \mathrm{ml}$ bovine serum albumin. Buffer B contained $50 \mathrm{mM}$ Tris$\mathrm{HCl}$ (pH 7.4), $150 \mathrm{mM} \mathrm{NaCl}, 5 \mathrm{mM}$ EDTA, $0.5 \%$ Nonidet P-40, $0.5 \%$ sodium deoxycholate, and $0.1 \%$ sodium dodecyl sulfate (SDS). After washing five times in $1.5 \mathrm{ml}$ buffer $\mathrm{B}, 100 \mu \mathrm{g}$ radiolabeled HeLa cell protein extract was added to the beads and incubated for $1 \mathrm{~h}$ with constant mixing. The radiolabeled extract had been precleared with $1 / 10 \mathrm{vol}$ of protein A Sepharose CL-4B in buffer B before being used. After centrifugation for $3 \mathrm{~min}$, the pellet was washed five times in $1.5 \mathrm{ml}$ buffer $B$ containing $23 \mathrm{U} / \mathrm{ml}$ kallikrein inactivator and $2 \mathrm{mM}$ PMSF. The $\left[{ }^{35}\right.$ S]methionine-labeled pellet was then boiled in Laemmli sample buffer, and the proteins were analyzed by SDS-polyacrylamide gel electrophoresis (PAGE) (29), followed by fluorography and autoradiography. Half of the ${ }^{32} \mathrm{P}$-labeled pellet was digested with DNase and RNase (Millipore Corp., Bedford, MA) at $0.5 \mathrm{mg} / \mathrm{ml}$ each for $30 \mathrm{~min}$ at $37^{\circ} \mathrm{C}$, and the proteins were resolved by SDS-PAGE. The other half of the pellet was phenol extracted, and any RNA was precipitated in ethanol. RNA analysis was performed in $7 \mathrm{M}$ urea, $8 \%$ polyacrylamide gels, then autoradiography as described elsewhere (2).
Antigen depletion. $\left[{ }^{35} \mathrm{~S}\right]$ methionine-labeled HeLa cell extract $(100 \mu \mathrm{g}$ of protein) was incubated with $40 \mu \mathrm{g}$ rabbit anti-RNA polymerase I IgG bound to protein A Sepharose CL-4B for $1 \mathrm{~h}$ at $4^{\circ} \mathrm{C}$ in buffer $\mathrm{B}$ to deplete the extract of RNA polymerase $I$. The depleted supernatant was then used in immunoprecipitation as the antigen source for human antinucleolar sera. In another experiment, $\left[{ }^{35} \mathrm{~S}\right]$ methionine-labeled HeLa cell extract was absorbed with $40 \mu \mathrm{g}$ human antinucleolar $\mathrm{IgG}$ as described and then probed with rabbit anti-RNA polymerase $I$. The same amounts of $\mathrm{IgG}$ from normal human serum and normal rabbit serum, as well as from a SLE serum with Sm specificity, were included in control experiments to ensure that changes observed were not due to nonspecific protein-protein interactions.

Microinjection of antibodies into $X$. laevis oocytes. IgG was obtained from a representative scleroderma serum (S18) by column chromatography on DEAE-cellulose (DE-52; Whatman Inc., Clifton, NJ) and was further purified by chromatography on protein A-Sepharose (Sigma Chemical Co., St. Louis, MO). IgG was concentrated to $2 \mathrm{mg} / \mathrm{ml}$ by vacuum dialysis against $P B S$. Antibodies were microinjected into nuclei of full-grown oocytes of $X$. laevis as described (30). Each oocyte nucleus received $10 \mathrm{nl}$ antibody solution. In some experiments, the solution was injected into the cytoplasm of the animal hemisphere of the oocytes. Purified IgG from normal human sera or monoclonal antibodies reacting with nonnucleolar constituents of oocytes were used as controls. Each experimental group consisted of six oocytes. $2 \mathrm{~h}$ after antibody injection, each oocyte received $0.1 \mu \mathrm{Ci} \alpha-\left[{ }^{32} \mathrm{P}\right] \mathrm{GTP}(10 \mathrm{mCi} / \mathrm{ml}$; Amersham Buchler $\mathrm{GmBH}$, Braunschweig, FRG) by injection into the cytoplasm. After an incubation time of $6 \mathrm{~h}$ at $20^{\circ} \mathrm{C}$, RNA was extracted and analyzed by electrophoresis in $1.5 \%$ agarose gels as described (30). The RNA corresponding to two oocytes was applied to each gel lane, air dried, and identified by autoradiography. rRNA from $X$. laevis ovary ribosomes and RNA from tobacco mosaic virus served as molecular weight markers.

\section{Results}

Antinucleolar antibodies in scleroderma sera. IgG antinucleolar antibodies were present in 31 of 208 scleroderma sera (15\%). These sera were selected for strong $(+++)$ nucleolar staining by indirect immunofluorescence on substrate Hep-2 cells. Nucleoplasmic staining was also present with some sera, but the designation of sera with antinucleolar antibodies in this screening assay was based on the criterion that nucleolar staining exceeded nucleoplasmic staining by at least one gradation of intensity. Nine of the antinucleolar positive sera gave a punctate or speckled nucleolar staining pattern, usually up to a serum dilution of $1: 2,560$ or higher. The other sera produced homogeneous or clumpy nucleolar staining and were classified according to a previous report on the association of antinuclear and antinucleolar antibodies in scleroderma (17).

In the present study, the antigen reactive with scleroderma antibodies that produce speckled nucleolar staining was further characterized.

Localization by light and electron microscopic immunocytochemistry of scleroderma antibodies with speckled nucleolar staining. The following immunofluorescence results were obtained with all nine sera with speckled nucleolar staining. Fig. 1 shows indirect immunofluorescence staining and phase-contrast microscopy as obtained with representative serum S18 using HeLa cells ( $a$ and $b$ ), Vero cells ( $c$ and $d$ ), and concanavalin-Astimulated human peripheral blood lymphocytes ( $e$ and $f$ ) as substrates. Note that in different phases of the cell cycle, different staining patterns were observed. Nucleolar staining that consisted of many fluorescent speckles in interphase cells changed to a few bright fluorescent spots in the area of condensed chromosomes of dividing cells (Fig. $1 c$, arrows). In concanavalin-A- 

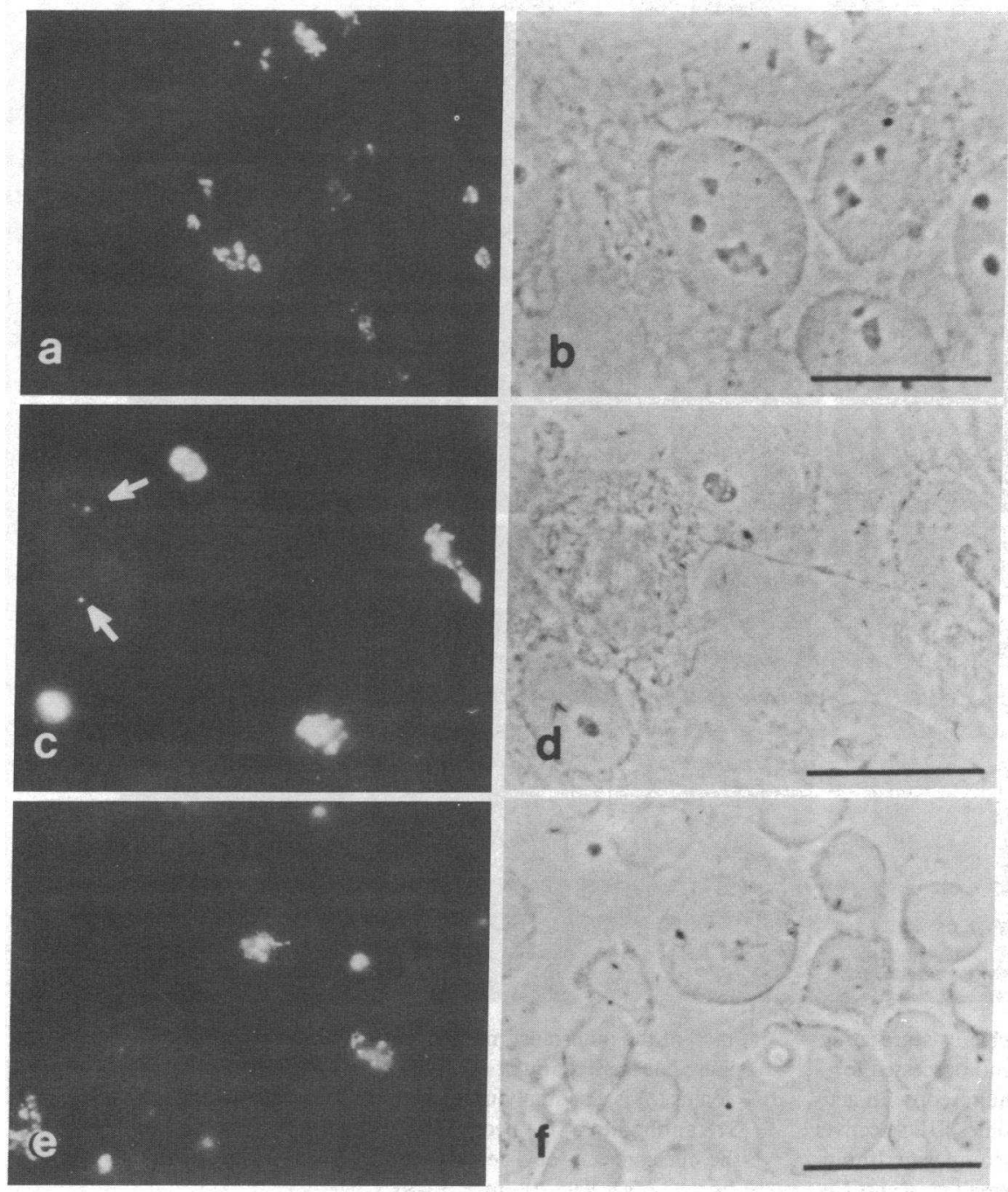

Figure 1. Immunofluorescence microscopy of HeLa cells (a), Vero cells $(c)$, and concanavalin A stimulated peripheral human blood lymphocytes $(e)$ after staining with antinucleolar antibodies (S18) from a patient with scleroderma. Nucleoli demonstrate a speckled immunofluorescence pattern of interphase cells. In a mitotic Vero cell, several bright fluorescent dots (arrows) are present that may represent nucleolar organizer regions. Weak nucleoplasmic staining is also present. Note increase of nucleolar staining in blast-transformed lymphocytes (large cells in $e$ and $f$ ). For comparison, the cells are also shown in phase contrast optics $(b, d, f)$. Bar, $20 \mu \mathrm{m} \times 1,450$. stimulated peripheral blood lymphocytes, increased intensity of nucleolar staining was observed in blast-transformed lymphocytes (Fig. $1 e$, large cells). Weak nucleoplasmic staining $(+)$ of interphase cells was also observed with these sera, whereas cytoplasmic staining was usually absent.

To further define the nature of the nucleolar antigens, we exposed Vero cells to the nucleolus-segregating drugs actinomycin D and DRB. After drug treatment, cells were processed for indirect immunofluorescence and phase-contrast microscopy. Actinomycin D-inactivated nucleoli show a typical segregation of the fibrillar component from the granular component (Fig. $2 b$ ), with the fibrillar component forming distinct nucleolar hemispheres (31-33). Antibodies demonstrating speckled nucleolar staining in untreated cells were now distinctly localized in the fibrillar regions of segregated nucleoli (Fig. $2 a$ ). Immunofluorescence staining was most prominent in small crescents at the outermost margins of the segregated fibrillar component. Little if any decoration of the granular structures that appeared dark in phase optics was observed. When DRB was added to Vero cells growing in culture, the normally compact nucleoli unraveled into extended beaded strands, segregating the nucleolus into granular and fibrillar regions $(34,35)$. Immunofluorescence staining of these cells using the same scleroderma anti- bodies resulted in binding with only fibrillar structures producing a "necklace" distribution of fluorescent dots dispersed throughout the nucleoplasm (Fig. 2, $c$ and $d$ ).

Electron miscroscopy was performed using reference serum S18 and rabbit anti-RNA polymerase I antibodies in the immunogold label technique. In this experiment, gold-antibody complexes were localized in the fibrillar centers of nucleoli in hepatocytes from normal and regenerating rat liver. IgG from scleroderma serum S18 was selectively enriched over the fibrillar centers and was not observed in the dense fibrillar component or the granular component of nucleoli (Fig. 3, $a$ and $b$ ). The same staining pattern was obtained with a rabbit anti-RNA polymerase I serum (Fig. $3 c$ ) showing distribution of gold-antibody complexes in the fibrillar centers, as had been reported previously (24).

\section{Interaction of antinucleolar antibodies from scleroderma sera with RNA polymerase I}

Double immunofluorescence staining. The enzyme RNA polymerase I has been shown by other investigators to be localized in nucleoli. The immunofluorescence patterns obtained with the human scleroderma sera depicted in Figs. 1 and 2, as well as the electron microscopic studies in Fig. 3, are morphologically 

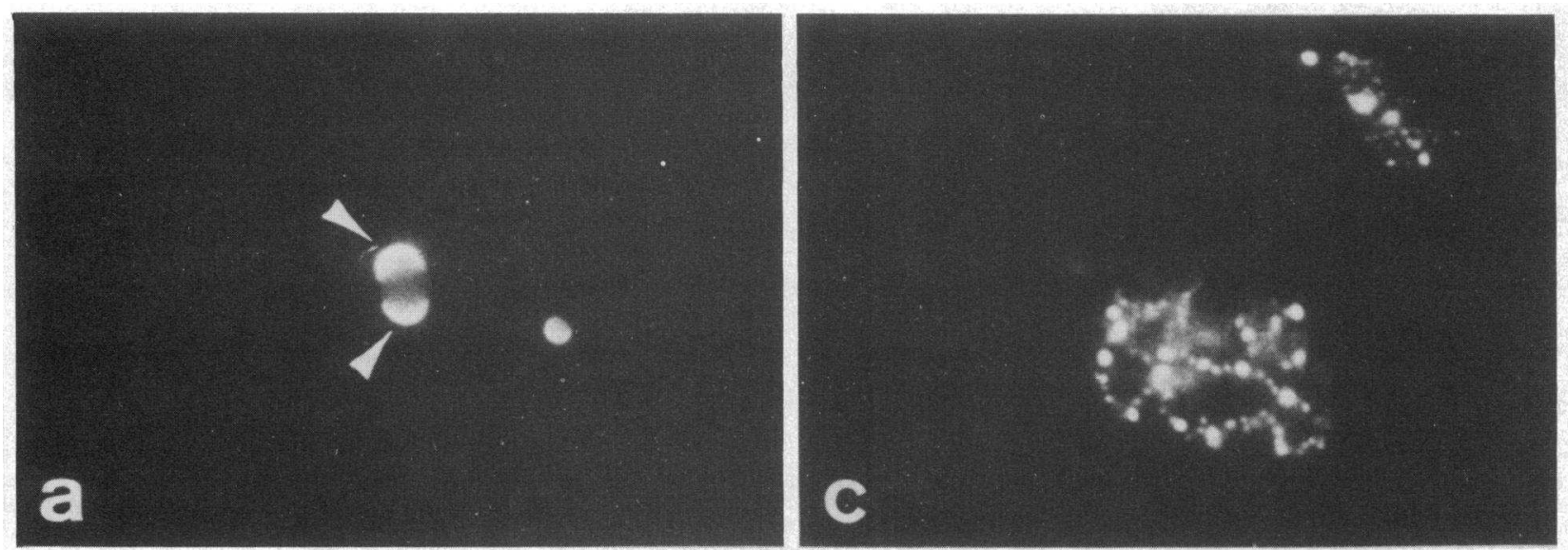

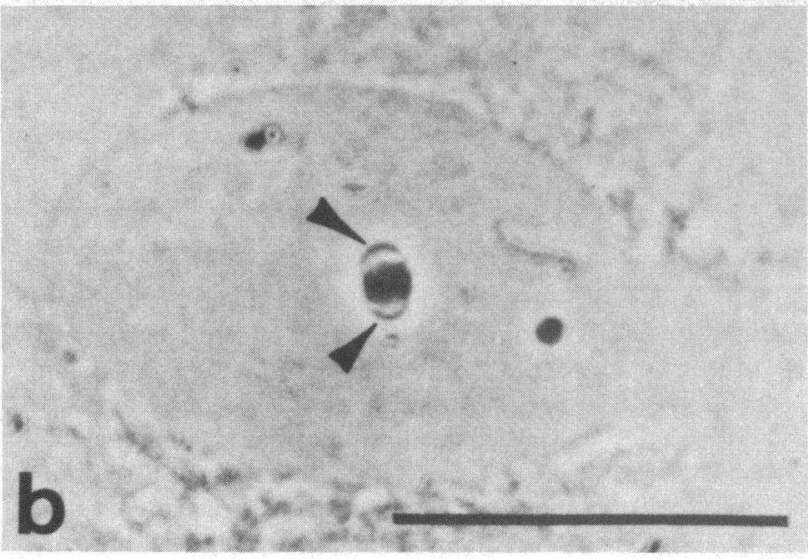

Figure 2. Cultured Vero cells were treated with nucleolus-segregating drugs actinomycin D ( $a$ and $b$ ) or DRB ( $c$ and $d)$ and processed for indirect immunofluorescence and phase-contrast microscopy. In actinomycin D segregated nucleoli, scleroderma antibodies $\$ 18$ selectively stained the fibrillar regions, as shown in (a) of this composite. Immunofluorescence staining is most prominent in two small crescents (ar-

similar to those obtained with rabbit anti-RNA polymerase I antibodies $(24,25)$. It remained to be demonstrated that identical subcellular structures were reactive with both antibodies by simultaneous staining. A human serum representative of speckled nucleolar staining (S18) and anti-RNA polymerase I rabbit serum were incubated simultaneously with Vero cells treated with DRB. The antigen-antibody reaction was visualized on the same substrate with a rhodamine anti-human IgG and fluorescein anti-rabbit IgG conjugate. In this experiment it was observed that both human antinucleolar and rabbit serum recognized the same nucleolar structures in location and conformation, so photomicrographs from these experiments were virtually superimposable (data not shown).

Immunoprecipitation. We then examined the molecular nature of the antigen reactive with human sera demonstrating speckled nucleolar staining. $\left[{ }^{35}\right.$ S $]$ methionine-labeled HeLa cell extract was used for immunoprecipitation. Nine sera with speckled nucleolar staining pattern uniformly immunoprecipitated 13 polypeptides (P1-P13) with mol wt of 210,000, 190,000, $155,000,130,000,120,000,80,000,64,000,62,000,42,000$, $25,000,18,000,16,000$, and 14,000. The results obtained with two representative sera (S18 and S124) are shown in Fig. $4 a$, lanes 2 and 3. Examination of the immunoprecipitates obtained

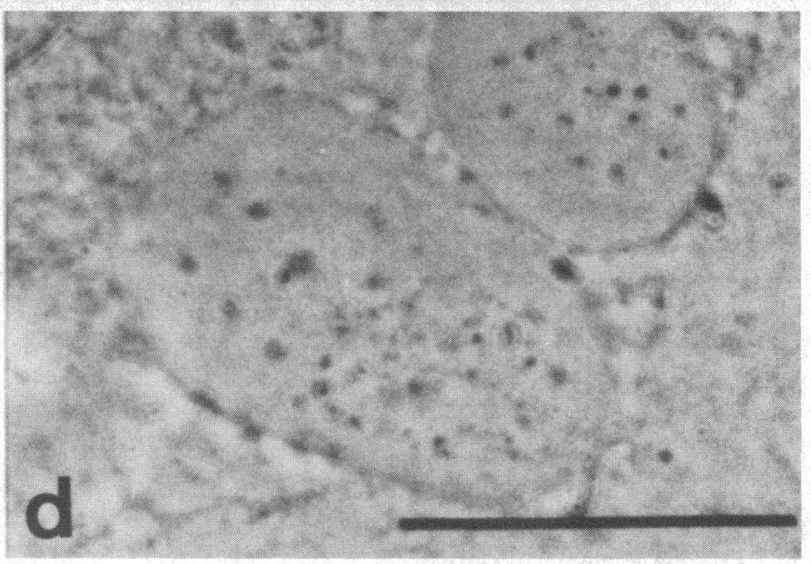

rows) at the outermost margins of the fibrillar regions. The dark (by phase contrast) granular component in the center of this compact nucleolus $(b)$ is essentially unstained. In Vero cells treated with DRB, S18 antibodies give a necklace type of staining dispersed throughout the nucleoplasm $(c)$. The same cell is also shown by phase-contrast microscopy $(d)$. Bar, $20 \mu \mathrm{m} \times 1,450$.

by the rabbit anti-RNA polymerase I antibodies side by side with the human antinucleolar antibodies revealed the same 13 polypeptides by SDS-PAGE and autoradiography (Fig. 4, lane 4). Fig. $4 b$ shows the same polypeptides as Fig. $4 a$, but better resolution of the high molecular weight polypeptides P1-P6 was obtained in 5\% SDS-polyacrylamide gel instead of $17.5 \%$ gel. Our control group, consisting of normal human sera and more than 100 autoimmune sera from patients with systemic lupus erythematosus, MCTD, or rheumatoid arthritis did not contain antibodies precipitating this polypeptide profile. Moreover, none of the sera from 120 SLE patients analyzed by immunoprecipitation in another study in this laboratory (manuscript in preparation), precipitated these 13 polypeptides. On the other hand, this pattern of 13 polypeptides was consistently produced by nine sera with speckled nucleolar immunofluorescence. Sera with other patterns of nucleolar reaction also did not produce this finding.

HeLa cells were labeled with [ ${ }^{32} \mathrm{P}$ ]orthophosphate and the cell lysate used to determine if any of the RNA polymerase I subunits were phosphoproteins and whether this enzyme was coprecipitated with any species of RNA. The polypeptides of mol wt 190,000 (P2), 80,000 (P6), 64,000 (P7), and 18,000 (P11) were phosphorylated as shown in Fig. 5, lane 4. This figure also 


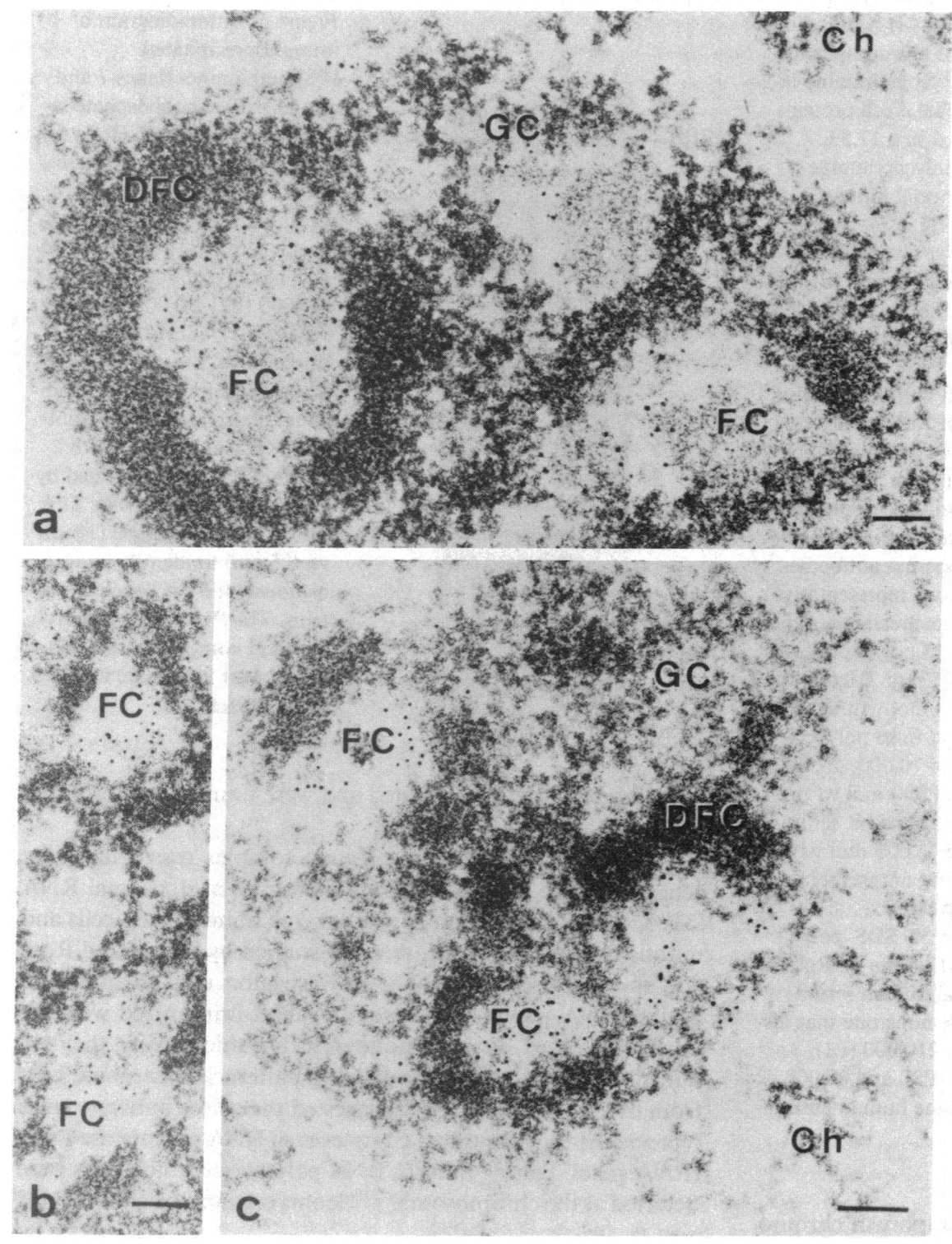

Figure 3. Binding of scleroderma antinucleolar IgG S18 $(a$ and $b$ ) and rabbit antibodies to RNA polymerase I $(c)$ to subnucleolar components in the hepatocytes of normal ( $a$ and $c$ ) and regenerating $(b)$ rat liver, as revealed by the electron microscopic immunogold label technique. The 5-nm gold particles (small black dots) are selectively enriched over the fibrillar centers $(F C)$, roundish zones of low contrast. The dense fibrillar components $(D F C)$ surrounding the fibrillar centers as well as the granular components $(G C)$ of the nucleoli are essentially free of gold particles after incubation with both antibodies. $(C h)$, chromatin surrounding the nucleoli. Bars, 0.1 $\mu \mathrm{m} \times 110,000(\mathrm{a}, \mathrm{b}), 0.1 \mu \mathrm{m} \times 135,000$. shows that a phosphoprotein of mol wt 35,000 (arrow), which was not labeled with $\left[{ }^{35} \mathrm{~S}\right]$ methionine, was precipitated as a phosphoprotein by $\mathrm{S} 18$ antibodies. In this series of experiments, a longer gel $(15 \mathrm{~cm}$ vs. $8.5 \mathrm{~cm})$ was used to identify unambiguously the ${ }^{32} \mathrm{P}$-labeled proteins. In many studies using acid-urea gels (see Methods), RNA was not coprecipitated with the RNA polymerase I complex, as opposed to anti-U1 RNP antibodies from a patient with MCTD, which precipitated the U1-RNA species (data not shown).

Immunoabsorption. To demonstrate further that the human antinucleolar and rabbit anti-RNA polymerase I antibodies interact with the same antigen, i.e., RNA polymerase I, we absorbed $\left[{ }^{35} \mathrm{~S}\right]$ methionine-labeled HeLa cell extract with the IgG fraction of rabbit antiserum. We then used this RNA polymerase I-depleted extract in an immunoprecipitation assay and showed that this preparation lacked the antigen recognized by our prototype antinucleolar serum S18 (Fig. 6, lane 2). In a reciprocal fashion, when HeLa cell extract was absorbed with this human serum and then probed with rabbit antiserum, the RNA polymerase I complex was not precipitated (Fig. 6, lane 4). In contrast, depletion of radiolabeled HeLa cell extract by autoantibodies of different immunological specificities, e.g., anti-Sm antibodies as in lane 5 , did not affect specific antigen recognition by antinucleolar scleroderma (Fig. 6, lane 6) or rabbit anti-RNA polymerase I IgG (data not shown). These findings support the earlier observations that RNA polymerase $I$ is the antigen recognized by certain antinucleolar antibodies in scleroderma sera.

Microinjection of antibodies into Xenopus laevis oocytes. Purified IgG from reference serum S18 and control antibodies were microinjected into $X$. laevis oocyte nuclei. In these experiments, a considerable reduction in the accumulation of newly synthesized 28S and 18S rRNA was observed as shown in Fig. 7 , lane 4 . This $1.5 \%$ agarose gel also shows that there was no significant effect when normal human serum IgG (lane 1 ) or monoclonal IgM antibody to DNA (lane 2) were injected into the nucleus of $X$. laevis oocytes. The monoclonal IgM antibodies to DNA did not interfere with transcription of the rRNA genes because they are excluded from the compact amplified nucleoli. 


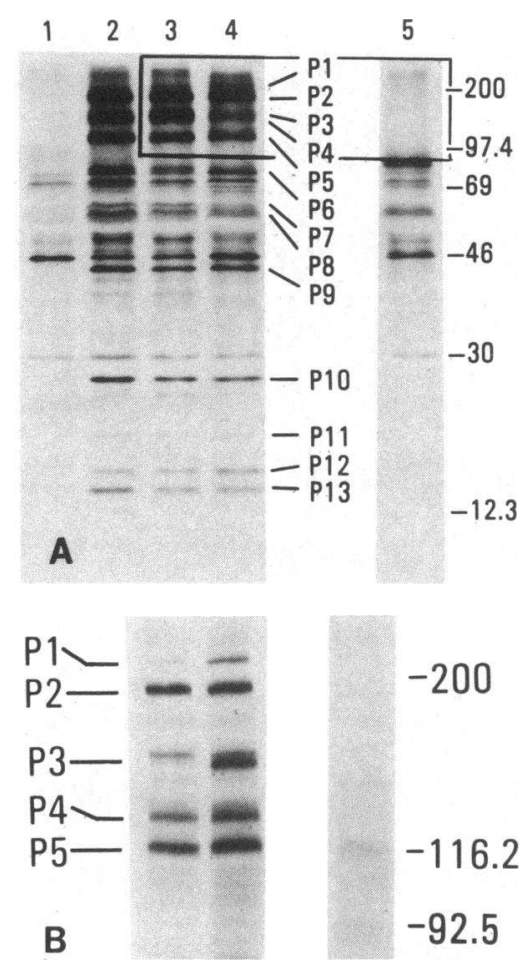

cipitated by normal human serum. In addition, control rabbit serum also brought down a protein of $80,000 \mathrm{~mol} \mathrm{wt}$. The $46,000 \mathrm{~mol} \mathrm{wt}$ protein is actin, the other polypeptides precipitated by normal sera are unknown. (B) Autoradiogram of immunoprecipitated

${ }^{35}$ S]methionine-labeled HeLa proteins resolved in a 5\% SDS-polyacrylamide gel. Antinucleolar scleroderma serum S18 (lane 1). Rabbit anti-RNA polymerase I antibodies (lane 2). Normal human serum (lane 3). This low-percent gel system was used to demonstrate that distinct high molecular weight polypeptides of mol wt 210,000 (P1), 190,000 (P2), 155,000 (P3), 130,000 (P4), 120,000 (P5), and 80,000 (P6) were immunoprecipitated with the rabbit and the human antinucleolar serum.

However, they inhibit transcription of the lampbrush chromosome loops (data not shown). Microinjection of antibodies S18 into the cytoplasm (lane 3) also had no effect on rRNA transcription since antibodies do not migrate through the nuclear pores (36).

Several attempts were made to identify the epitope or epitopes of the RNA polymerase I complex reactive with certain scleroderma autoantibodies. Extractable whole HeLa cell proteins, isolated nucleoli as well as purified RNA polymerase I from Morris hepatoma 3942A, were electrophoretically transferred to nitrocellulose for immunoblotting. At present, no conclusive results concerning the antigenic subunit were obtained, although a protein of mol wt 190,000 corresponding to one of the large subunits of RNA polymerase I from Morris hepatoma $3924 \mathrm{~A}$ has been weakly reactive with some sera.

\section{Discussion}

In the present study, we have provided evidence by immunocytochemical localization, immunoprecipitation, and microinjection of autoimmune antibodies into living cells that the RNA polymerase I complex was the antigen recognized by a subset of antinucleolar antibodies from scleroderma sera. Anti-RNA polymerase I autoantibodies were present in $4 \%$ of the 208

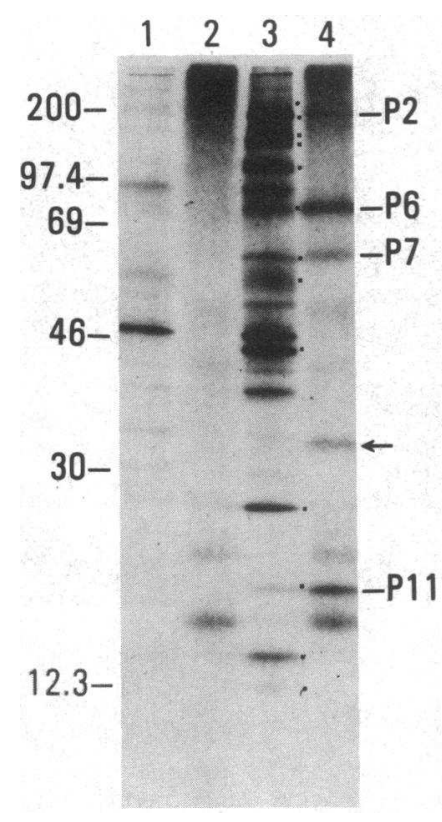

Figure 5. Autoradiogram of immunoprecipitated

$\left[{ }^{35}\right.$ S]methionine- (lanes 1 and 3) and $\left.{ }^{32} \mathrm{P}\right]$ orthophosphate-labeled (lanes 2 and 4) HeLa cell proteins digested with RNase and DNase. Normal human serum (lanes $I$ and 2). Antinucleolar serum S18 (lanes 3 and 4). The polypeptides of mol wt 190,000 (P2), 80,000 (P6), 64,000 (P7), and 18,000 (P11) labeled with S-methionine are also phosphoproteins. An additional phosphoprotein of mol wt 35,000 , not labeled with $\left[{ }^{35}\right.$ S]methionine, is detected by autoradiography (arrow). This study used a longer gel $(15 \mathrm{~cm}$ vs. $8.5 \mathrm{~cm}$ ) to identify unambiguously the $\left.{ }^{32} \mathrm{P}\right]$ labeled proteins. The P1-P13 RNA polymerase I complex in this and subsequent figures are identified by black dots.

scleroderma patients examined and were found to be restricted to this autoimmune disease.

RNA polymerase I is an enzyme complex transcribing the genes that code for the precursor molecules of ribosomal RNA $(31,37)$. The distribution of this enzyme in interphase cells and mitotic chromosomes was recently studied by Scheer and Rose (24) and Scheer et al. (25). These investigators used an antiserum against RNA polymerase I from a rabbit immunized with the purified enzyme. By immunofluorescence microscopy, they obtained a punctate nucleolar staining pattern in interphase cells from different species. They suggested that these punctate areas represented transcriptional complexes of RNA polymerase I and rRNA genes. During mitosis, RNA polymerase I molecules were detected at the chromosomal nucleolus organizer regions. Tran-

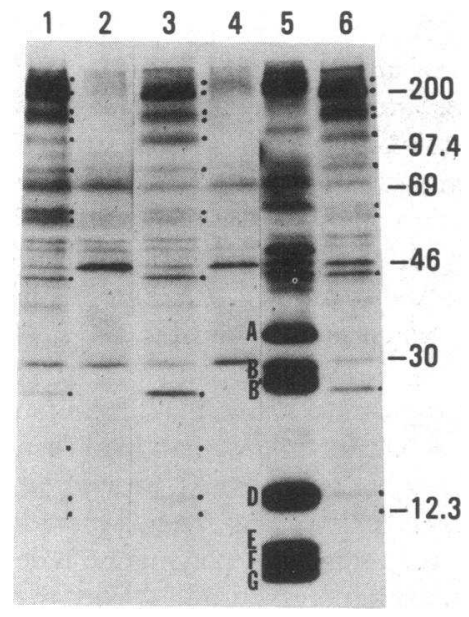

Figure 6. Depletion of RNA polymerase I from $\left[{ }^{35}\right.$ S ] HeLa cell extract by rabbit and human antibodies. RNA polymerase I immunoprecipitated by rabbit antibodies (lane 1). Immunoprecipitate obtained with human antinucleolar antibodies S18 (lane 2) with supernatant from lane $l$ experiment. Immunoprecipitate obtained with antinucleolar antibodies S18 with unabsorbed extract (lane 3). Immunoprecipitate obtained with rabbit anti-RNA polymerase I antibodies with supernatant from lane 3 experiment. Anti-Sm serum from a patient with SLE showed a different immunoprecipitation profile (proteins A-G, lane 5). The supernatant from lane 5 experiment still contained the entire RNA polymerase I complex that was immunoprecipitated with serum S18 (lane 6). 


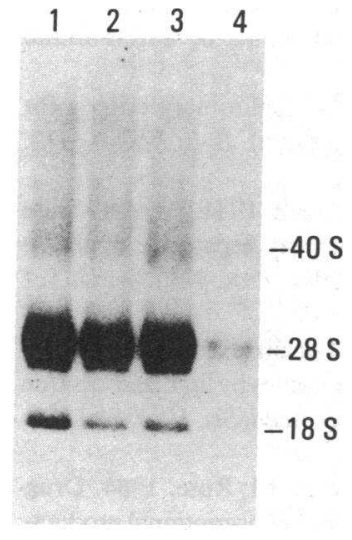

Figure 7. Autoradiogram of RNA from $X$. laevis oocytes radiolabeled after microinjection of various antibodies. Intranuclear injection of monoclonal IgM-antibody to DNA (lane 2). Injection of purified IgG from scleroderma serum S18 into the cytoplasm (lane 3) and nucleus (lane 4). Introduction of the scleroderma antibodies S18 into the oocyte nuclei causes a considerable reduction in the accumulation of newly synthesized $28 \mathrm{~S}$ and 18S RNAs. 40S indicates position of the pre-rRNA.

scriptionally active rRNA genes were localized by electron microscopic immunocytochemistry in the fibrillar centers of nucleoli.

The speckled nucleolar staining pattern we observed with a subset of antinucleolar antibodies from scleroderma patients was very similar to, if not identical with, the pattern described for the rabbit anti-RNA polymerase I serum by Scheer and Rose (24). An anti-RNA polymerase I serum from a rabbit was also used in a series of experiments in this study. Double immunofluorescence staining showed that human speckled antinucleolar IgG decorated the same nucleolar structures as the rabbit antibodies. Localization of autoantibodies in the fibrillar regions of drug-segregated nucleoli and, more importantly, their localization by electron microscopy in fibrillar centers (24), which are the sites of rRNA gene transcription, gave confirming evidence of binding with RNA polymerase I. Interestingly, these scleroderma antibodies produced nucleolar immunofluorescence staining not only in human but also in rodent, avian, and amphibian cells, suggesting that the epitope is highly conserved during evolution. When scleroderma antibodies with speckled nucleolar staining in indirect immunofluorescence were microinjected into $X$. laevis oocytes, a dramatic decrease in the accumulation of newly transcribed ribosomal RNA was observed. The human antibodies thus appear to be effective in interfering with the function of RNA polymerase I.

On a macromolecular level, both scleroderma antinucleolar antibodies and rabbit anti-RNA polymerase I antibodies immunoprecipitated identical polypeptides ranging from mol wt 210,000 to 14,000 . RNA polymerase $I$ is a complex enzyme previously reported to be composed of eight subunits in Morris hepatoma 3942A ranging in size from mol wt 190,000 to 17,500 (23). By immunoprecipitation with specific antibody, we revealed five additional $\left[{ }^{35}\right.$ S $]$ methionine-labeled polypeptides present in HeLa cell extract that had not been reported to be part of the enzyme purified by column chromatography from rat hepatoma. Further investigations will determine whether these additional polypeptides are part of the RNA polymerase I complex reflecting additional subunits or merely posttranslational modifications of previously described subunits. It is also conceivable that some of these additional polypeptides represent tightly bound factors of this enzyme that may be associated with initiation or termination of rRNA gene transcription (38), Recently, immunoprecipitation of intrinsically radiolabeled DNA polymerase $\alpha$ with a monoclonal antibody resulted in the identification of an additional catalytic component of this enzyme that had been previously unknown (39). It seems likely that the use of specific antibody for immunoprecipitation will also facilitate further characterization of RNA polymerase I.

In a previous study, all RNA polymerase I subunits from rat hepatoma could be phosphorylated by an endogenous protein kinase associated with this enzyme (40-41). Autoradiography of in vivo ${ }^{32} \mathrm{P}$-labeled RNA polymerase I obtained by immunoprecipitation in this study revealed only four phosphoproteins (P2, P6, P7, and P11) as part of the complex. Since the degree of phosphorylation of this enzyme paralleled transcriptional activity as shown in previous studies $(23,40)$, the present findings might reflect a less active form of RNA polymerase I readily extractable from HeLa cells. At present it is unknown how exactly the phosphorylation is regulated in vivo.

In previous reports by Stetler and co-workers $(40,42)$, antibodies to RNA polymerase I were detected by radioimmunoassay and by immunoblotting in $100 \%$ of patients with SLE and MCTD, and in $78 \%$ of patients with rheumatoid arthritis. However, we were only able to immunoprecipitate the RNA polymerase I complex with scleroderma sera that produced a speckled nucleolar immunofluorescence pattern and not with any other sera, including scleroderma sera with different staining patterns. The discrepancies between the work of Stetler and associates and this study may be related to differences in techniques used. A critical assay used by the previous authors was a radioimmunoassay in which they employed a preparation of rodent RNA polymerase I as the antigen to coat the wells of plastic immunoassay plates. In the present study, immunocytochemical localization of antibody, immunoprecipitation of intrinsically labeled antigens, and microinjection of antibody into living cells were the main techniques used. These considerations, however, do not completely clarify the discrepancies. If RNA polymerase I, however, is an enzyme predominantly localized in the nucleolus, as has been previously shown $(24,25,31,37)$, it is difficult to understand why sera from SLE, MCTD, and rheumatoid arthritis patients rarely demonstrate nucleolar staining in indirect immunofluorescence (15-17). It would be reasonable to expect that many SLE, MCTD, and rheumatoid arthritis sera would show nucleolar staining with the high frequency of anti-RNA polymerase I antibodies reported by the previous investigators. Several explanations concerning these discrepancies are now under investigation and they include the possibility that epitopes recognized by SLE, MCTD, and rheumatoid arthritis sera may not be accessible to antibody in the indirect immunofluorescence or immunoprecipitation assays.

The association of speckled nucleolar staining by serum antibodies with the diagnosis of scleroderma was noted in an earlier study (17). We have extended the studies to show that the reactive antigen demonstrates properties very similar to RNA polymerase I. Our knowledge of the function of this key enzyme in the nucleolus and the further characterization of the epitope may lead to another step in elucidating the immune response in scleroderma.

\section{Acknowledgments}

We wish to thank Thomas H. Hoger and Jan-M. Peters, of the German Cancer Research Center, Institute of Cell and Tumor Biology, Heidelberg, FRG, for skillfully performing the electron microscopic immunocytochemistry presented in this study. We also thank Dr. G. Rhodes and Dr. A. M. Francoeur for helpful suggestions.

This is publication number 3928BCR Scripps Clinic and Research Foundation. This work was supported by National Institutes of Health grants AM-32063 (Dr. Tan), AI-10386 (Dr. Tan), and AI-21084 (Dr. 
Rose). Dr. Reimer is supported by grant Re 585/1-1 from Deutsche Forschungsgemeinschaft. Dr. Rose is the recipient of a Research Career Development Award from the National Cancer Institute.

\section{References}

1. Tan, E. M. 1982. Autoantibodies to nuclear antigens (ANA): their immunobiology and medicine. Adv. Immunol. 33:167-240.

2. Lerner, M. R., and J. A. Steitz. 1979. Antibodies to small nuclear RNAs complexed with proteins are produced by patients with systemic lupus erythematosus. Proc. Natl. Acad. Sci. USA. 76:5495-5499.

3. Francoeur, A. M., E. K. L. Chan, J. I. Garrels, and M. B. Mathews. 1985. Characterization and purification of lupus antigen $\mathrm{La}$, an RNA binding protein. Mol. Cell. Biol. 5:586-590.

4. Pizer, L. I., J.-S. Deng, R. M. Sternberg, and E. M. Tan. 1983. Characterization of a phosphoprotein associated with the SS-B/La nuclear antigen in adenovirus-infected and uninfected KB cells. Mol. Cell. Biol. 3:1235-1245.

5. Mathews, M. B., and R. M. Bernstein. 1983. Myositis autoantibody inhibits histidyl-tRNA synthetase: a model for autoimmunity. Nature (Lond.). 304:177-179.

6. Douvas, A. S., M. Achten, and E. M. Tan. 1979. Identification of a nuclear protein (Scl-70) as a unique target of human antinuclear antibodies in scleroderma. J. Biol. Chem. 254:10514-10522.

7. Moroi, Y., C. Peebles, M. J. Fritzler, J. C. Steigerwald, and E. M. Tan. 1980. Autoantibody to centromere (kinetochore) in scleroderma sera. Proc. Natl. Acad. Sci. USA. 77:1627-1631.

8. Cox, J. V., E. A. Schenk, and J. B. Olmsted. 1983. Human anticentromere antibodies: distribution, characterization of antigens, and effect on microtubule organization. Cell. 35:331-339.

9. Earnshaw, W. C., N. Halligan, C. Cooke, and N. Rothfield. 1984. The kinetochore is part of the metaphase chromosome scaffold. J. Cell Biol. 98:352-357.

10. Shero, J. H., B. Bordwell, N. F. Rothfield, and W. C. Earnshaw. 1986. High titers of autoantibodies of topoisomerase I (Scl-70) in sera from scleroderma patients. Science (Wash. DC). 231:737-740.

11. Yang, V. W., M. R. Lerner, J. A. Steitz, and S. J. Flint. 1981. A small nuclear ribonucleoprotein is required for splicing of adenoviral early RNA sequences. Proc. Natl. Acad. Sci. USA. 78:1371-1375.

12. Lerner, M. R., N. C. Andrews, G. Miller, and J. A. Steitz. 1981 Two small RNAs encoded by Epstein-Barr virus and complexed with protein are precipitated by antibodies from patients with systemic lupus erythematosus. Proc. Natl. Acad. Sci. USA. 78:805-809.

13. Stefano, J. E. 1984. Purified lupus antigen La recognizes an oligouridylate stretch common to the $\mathbf{3}^{\prime}$ termini of RNA polymerase III transcript. Cell. 36:145-154.

14. Earnshaw, W. C., K. F. Sullivan, W. Saunders, D. S. Cleveland, N. F. Rothfield. 1985. Identification and molecular cloning of CENP. $B$, a human centromere protein recognized by all human anticentromere antibodies (ACA). Clin. Res. 33:591a. (Abstr.)

15. Ritchie, R. F. 1970. Antinucleolar antibodies: their frequency and diagnostic association. N. Engl. J. Med. 282:1174-1178.

16. Pinnas, J. L., J. D. Northway, and E. M. Tan. 1973. Antinucleolar antibodies in human sera. J. Immunol. 111:996-1004.

17. Bernstein, R. M., J. C. Steigerwald, and E. M. Tan. 1982. Association of antinuclear and antinucleolar antibodies in progressive systemic sclerosis. Clin. Exp. Immunol. 48:43-51.

18. Reddy, R., E. M. Tan, D. Henning, K. Nogha, and H. Busch 1983. Detection of a nucleolar 7-2 ribonucleoprotein and a cytoplasmic 8-2 ribonucleoprotein with autoantibodies from patients with scleroderma. J. Biol. Chem. 258:1383-1386.

19. Hashimoto, C., and J. A. Steitz. 1983. Sequential association of nucleolar 7-2 RNA with two different autoantigens. J. Biol. Chem. 258: 1379-1382.

20. Lischwe, M. A., R. Reddy, R. L. Ochs, L. C. Yeoman, E. M. Tan, M. Reichlin, and H. Busch. 1985. Purification of a nucleolar scleroderma antigen $\left(\mathrm{M}_{\mathrm{r}}=34,000 ; \mathrm{pI}, 8.5\right)$ rich in $\mathrm{N}^{\mathrm{G}}, \mathrm{N}^{\mathrm{G}}$-dimethylarginine. J. Biol. Chem. 260:14304-14310.
21. Ochs, R. L., M. A. Lischwe, W. H. Spohn, and H. Busch. 1985. Fibrillarin: a new protein of the nucleolus identified by autoimmune sera. Biol. Chem. 54:123-134.

22. Masi, A. T., and G. P. Rodnan. 1981. Preliminary criteria for the classification of systemic sclerosis (scleroderma). Bull. Rheum. Dis. $31: 1-6$.

23. Rose, K. M., D. A. Stetler, and S. T. Jacob. 1981. Protein kinase activity of RNA polymerase I purified from rat hepatoma: probable function of $\mathrm{M}_{\mathrm{r}} 42,000$ and 46,600 polypeptides. Proc. Natl. Acad. Sci. USA. 78:2833-2837.

24. Scheer, U., and K. M. Rose. 1984. Localization of RNA polymerase I in interphase cells and mitotic chromosomes by light and electron microscopic immunocytochemistry. Proc. Natl. Acad. Sci. USA. 81:14311435.

25. Scheer, U., B. Hugle, R. Hazan, and K. M. Rose. 1984. Druginduced dispersal of transcribed rRNA genes and transcriptional products: immunolocalization and silver staining of different nucleolar components in rat cells treated with 5,6-dichloro- $\beta$-D-ribofuranosylbenzimidazole. J. Cell Biol. 99:672-679.

26. Liu, S. L., and K. M. Rose. Lipopolysaccharide mediated induction of RNA polymerase I activity and amount in murine B-lymphocytes. J. Biol. Chem., in press.

27. Reimer, G., R. L. Rubin, B. L. Kotzin, and E. M. Tan. 1984 Anti-native DNA antibodies from autoimmune sera also bind to DNA in mitochondria. J. Immunol. 133:2532-2536.

28. Francoeur, A. M., and M. B. Mathews. 1982. Interaction between VA RNA and the lupus antigen La: formation of a ribonucleoprotein particle in vitro. Proc. Natl. Acad. Sci. USA. 79:6772-6776.

29. Laemmli, U. K. 1970. Cleavage of structural proteins during the assembly of the head of bacteriophage T4. Nature (Lond.). 227:680-685.

30. Scheer, U., H. Hinssen, W. W. Franke, and B. M. Jockusch. 1984. Microinjection of actin-binding proteins and actin antibodies demonstrates involvement of nuclear actin in transcription of lampbrush chromosomes. Cell. 39:1431-1435.

31. Busch, H., and K. Smetana. 1970. The Nucleolus. Academic Press, Inc., New York. 626 pp.

32. Bernhard, W. 1971. Adv. Cytopharmacol. 1:49.

33. Simard, R., Y. Langelier, R. Mandeville, N. Maestracci, and A. Royal. 1974. The Cell Nucleus. Academic Press, Inc., New York. 3:447.

34. Granick, D. 1975. Nucleolar necklaces in chick embryo fibroblast cells. I. Formation of necklaces by dichlororibobenzimidazole and other adenosine analogues that decrease RNA synthesis and degrade preribosomes. J. Cell Biol. 65:398-417.

35. Granick, D. 1975. Nucleolar necklaces in chick embryo fibroblast cells. II. Microscope observations of the effect of adenosine analogues on nucleolar necklace formation. J. Cell Biol. 65:418-427.

36. Einck, L., and M. Bustin. 1984. Functional histone antibody fragments traverse the nuclear envelope. J. Cell Biol. 98:205-213.

37. Rose, K. M., D. A. Stetler, and S. T. Jacob. 1983. Enzymes of Nucleic Acid Synthesis and Modification. CRC Press, Boca Raton, FL. 2:43-74.

38. Wandelt, C., and I. Grummt. 1983. Formation of stable preinitiation complexes is a prerequisite for ribosomal DNA transcription in vitro. Nucl. Acids Res. 11:3795-3809.

39. Karawya, E., J. Swack, W. Albert, J. Fedorko, J. D. Minna, and S. H. Wilson. 1984. Identification of a higher molecular weight DNA polymerase $\alpha$ catalytic polypeptide in monkey cells by monoclonal antibody. Proc. Natl. Acad. Sci. USA. 81:7777-7781.

40. Stetler, D. A., and S. T. Jacob. 1984. Phosphorylation of RNA polymerase I augments its interaction with autoantibodies of systemic lupus erythematosus patients. J. Biol. Chem. 259:13629-13632.

41. Duceman, B. W., K. M. Rose, and S. T. Jacob. 1981. Activation of purified hepatoma RNA polymerase I by homologous protein kinase NII. J. Biol. Chem. 256:10755-10758.

42. Stetler, D. A., K. M. Rose, M. E. Wenger, C. M. Berlin, and S. T. Jacob. 1982. Antibodies to distinct polypeptides of RNA polymerase I in sera from patients with rheumatic disease. Proc. Natl. Acad. Sci. USA. 79:7499-7503. 